\title{
Impact of low donor to recipient weight ratios on cardiac transplantation
}

\author{
Senthil Nathan Jayarajan, MD, ${ }^{a}$ Sharven Taghavi, MD, ${ }^{a}$ Eugene Komaroff, $\mathrm{PhD},{ }^{\mathrm{b}}$ and Abeel A. Mangi, $\mathrm{MD}^{\mathrm{c}}$
}

Background: International Society of Heart and Lung Transplantation guidelines for adult heart transplantation (HT) suggest a donor to recipient body weight ratio (WR) of greater than 0.8 . For female to male transplants, a WR of greater than 0.9 is recommended.

\begin{abstract}
Methods: The United Network for Organ Sharing database was examined for adult HT from 1999 to 2011. Controls with a WR of 0.9 or greater (normal donor to recipient weight ratio) were compared with patients with a WR of 0.6 to 0.89 (WRL) and a WR of less than 0.59 (WRVL). The primary measured outcome was survival.

Results: Of the 21,928 patients undergoing HT, 14,592 (66.6\%) were performed with a normal donor to recipient weight ratio, $7212(32.9 \%)$ were performed with WRL, and $124(0.6 \%)$ were performed with WRVL. In male donor to male recipient, male donor to female recipient, and female donor to female recipient HT, the use of WRL did not influence median survival $(P=.3621)$ and was not associated with increased mortality $(P=.7273)$. In female donor to male recipient HT, WRL was associated with decreased median survival (435 days, $P=.0241$ ) and was associated with increased mortality (hazard ratio, $1.201 ; P=.0383$ ).

Conclusions: HT can be safely performed using WRL donors between sex-matched and male to female transplants. However, in female to male transplants, WRL donors are associated with decreased survival. Although clinical circumstances will guide decision making, consensus criteria may be revisited to liberalize the pool of acceptable donors in an era of unprecedented donor shortage. (J Thorac Cardiovasc Surg 2013;146:1538-43)
\end{abstract}

Heart transplantation (HT) continues to be the accepted therapy for end-stage heart failure. Although morbidity and mortality continue to decrease, limited donor availability has led to an increase in waiting list times and increases in waiting list mortality. ${ }^{1}$ There have been increasing efforts at expanding the donor pool by extending donor criteria. The use of donor hearts once thought to be unsuitable for transplant because of structural or functional deficits has shown to be safe for certain patients. ${ }^{2-10}$ The use of older donors ${ }^{5,11-13}$ and organs with longer ischemic times has also helped expand the donor pool. ${ }^{14-16}$ Sex-mismatched donors have also been used, albeit with increased adverse events. ${ }^{17}$

A previous study has shown that undersized donors with weight mismatch greater than $20 \%$ do not result in increased mortality, except in recipients with elevated pulmonary vascular resistances. ${ }^{18}$ However, data on the use of underweight heart transplant are conflicting. ${ }^{18-20}$

From the Department of Surgery, ${ }^{\mathrm{a}}$ Temple University Hospital, and the School of Public Health, ${ }^{\text {b }}$ Temple University, Philadelphia, Pa; and the Section of Cardiac Surgery, ${ }^{\mathrm{c}}$ Department of Surgery, Yale School of Medicine, New Haven, Conn. Disclosures: Authors have nothing to disclose with regard to commercial support.

Received for publication Jan 23, 2013; revisions received May 19, 2013; accepted for publication June 27, 2013; available ahead of print Aug 5, 2013.

Address for reprints: Abeel A. Mangi, MD, Center for Advanced Heart Failure, Mechanical Circulatory Support and Heart Transplantation, Yale University School of Medicine, Boardman 204, 330 Cedar St, New Haven, CT 06520

(E-mail: abeel.mangi@yale.edu).

0022-5223/\$36.00

Copyright (c) 2013 by The American Association for Thoracic Surgery

http://dx.doi.org/10.1016/j.jtcvs.2013.06.028
International Society of Heart and Lung Transplantation adult heart transplant donor guidelines caution the use of donors to within $20 \%$ of the recipient's body weight. When female donors are considered for male recipients, a $10 \%$ weight mismatch limit is recommended. In this study, we attempted to determine if this donor to recipient body weight ratio criterion could be safely extended. ${ }^{21}$

\section{METHODS \\ Data Source}

After Institutional Review Board approval, public files from the United Network for Organ Sharing (UNOS) registry were reviewed for adult patients receiving primary HT from 1998 to 2011. A total of 21,928 patients underwent orthotopic HT during this period. Of these, 7212 $(32.9 \%)$ were performed with selected underweight donors with a donor to recipient body weight of $60 \%$ to $80 \%$ (WRL). In addition, 124 $(0.6 \%)$ were performed with a carefully selected donor to recipient body weight ratio of less than $60 \%$ (WRVL). These 2 cohorts were compared with 14,592 patients $(66.6 \%)$ with ideally matched donors.

\section{Statistical Analysis}

$P<.05$ was considered to be statistically significant. All data analyses were performed using SAS, version 9.2 (SAS Institute, Cary, $\mathrm{NC})$. Continuous variables are presented as mean $\pm \mathrm{SD}$, and categorical variables are reported as percentages of the total number of data points available for that field. Analysis of variance, Student $t$ test, and $\chi^{2}$ test were used to analyze continuous and categorical variables. Kaplan-Meier methods with log-rank test and Cox proportional hazards regression were used to analyze median survival and differences between groups. For survival analysis, female donor to male recipient HT determined the division into 2 cohorts, because they experienced different selection criteria based on International Society of Heart and Lung Transplantation 


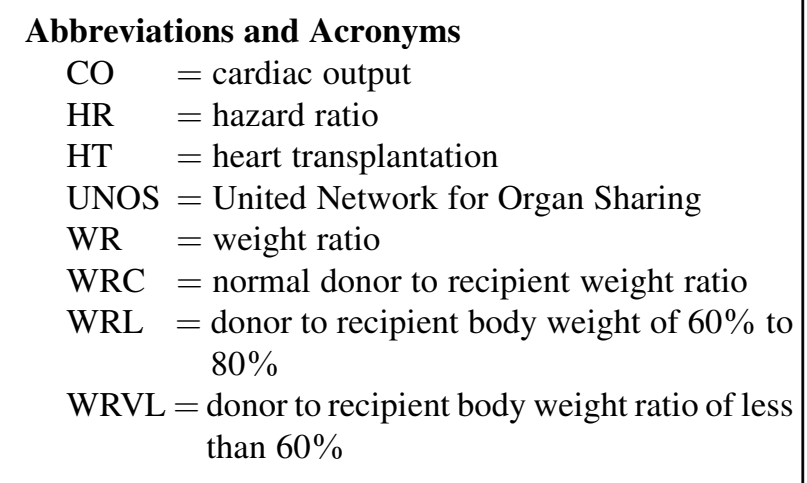

guidelines before transplantation. The analyses were applied separately to these cohorts.

Individual propensity scores were calculated for both cohorts based on generally accepted transplant criteria (ie, female to male transplants $>0.9$ and other transplants $>0.8$ ). The female to male transplant cohort propensity scores were based on the following factors: recipient age, donor age, ischemia time, recipient cardiac output (CO) before transplantation, pulmonary vascular resistance, days on status 1a, HLA mismatch, race mismatch, and transplant year. The other cohort used the following factors to calculate propensity scores: recipient age, donor age, recipient sex, donor sex, ischemia time, recipient $\mathrm{CO}$ before transplantation, pulmonary vascular resistance, days on status 1a, HLA mismatch, race mismatch, and transplant year.

The propensity scores were used to determine 1:1 matching for the Kaplan-Meier analyses. The weight mismatch groups were included in the Cox proportional hazards model, stratified by propensity score quartiles, along with all covariates that were statistically significant on univariate survival analysis.

\section{RESULTS}

\section{Recipient Characteristics}

Recipient characteristics are shown in Table 1 . Of the 21,928 patients undergoing HT, 14,592 $(66.6 \%)$ were performed with normal donor to recipient weight ratio (WRC), $7212(32.9 \%)$ were performed with selected donors who had a low donor to recipient weight ratio (WRL), and $124(0.6 \%)$ were performed with carefully selected donors who had a very low donor to recipient weight ratio (WRVL). Coronary artery disease and dilated cardiomyopathy were the most common indications for HT in all groups. There was no difference in recipient age $(P=.9729)$. WRC was less likely to be male $(74.7 \%)$ than WRL $(80.3 \%)$ or WRVL $(77.4 \%)(P<.0001)$. WRC recipients were most likely to be Hispanic $(7.5 \%)$ and Asian $(3 \%)$, whereas WRVL recipients were more likely to be white $(76.6 \%)$ and black $(17.7 \%)(P<.0001)$. WRC had the highest pulmonary vascular resistance (PVR) (2.6 vs 2.4 for WRL and WRVL; $P<.0001)$ and the lowest CO (4.4 vs 4.7 vs 4.9 for WRC vs WRL vs WRVL, respectively; $P<.0001)$.

\section{Donor Characteristics}

Donor characteristics are shown in Table 1. WRC had a lower donor age than WRVL, but it was greater than
WRL ( 32.3 vs 30.1 vs 35.4 years for WRC vs WRL vs WRVL; $P<.0001)$. WRC had the greatest mean body mass index ( $27.8 \mathrm{vs} 24.2 \mathrm{vs} 20.6 \mathrm{~kg} / \mathrm{m}^{2}$ for WRC vs WRL vs WRVL, respectively; $P<.0001)$. WRC was less likely to be male than WRL, but more likely than WRVL (70.4\% vs $72.6 \%$ vs $67.7 \%$ for WRC vs WRL vs WRVL, respectively; $P<.0001)$. WRC was most likely to be diabetic ( $2.8 \%$ vs $1.5 \%$ vs $1.6 \%$ for WRC vs WRL vs WRVL, respectively; $P<.0001)$.

\section{Transplant Characteristics}

Transplant characteristics are summarized in Table 1. WRVL was most likely to have sex mismatch $(30.7 \%$ vs $29.3 \%$ vs $25.3 \%$ for WRVL vs WRC vs WRL, respectively; $P<.0001)$ and the greatest ischemic time (3.3 vs 3.2 hours for WRVL vs WRC and WRL; $P<.0001)$. The 2 groups were evenly matched regarding race mismatch, total HLA mismatches, and length of stay.

\section{Survival}

Sex-matched (male to male, female to female) and male to female heart transplant. There are 12,192 patients in the WRC group, 6025 in the WRL group, and 99 in the WRVL group. Kaplan-Meier analysis of the propensitymatched data set for all other transplants is shown in Figure 1. Median survivals of the entire cohort for the WRC (3982 days) and WRL (4054 days) groups were not significantly different $(P=.3621)$. This was true when male to male HTs (3982 vs 4054 days for WRC vs WRL; $P=.4049$ ), female to female HTs (3802 vs 3770 days for WRC vs WRL; $P=.9667$ ), and male to female HTs (3982 vs 4054 days for WRC vs WRL; $P=.4049$ ) were analyzed individually. Results of the multivariate survival analysis stratified by propensity score quartiles are shown in Table 2. There was no greater likelihood of mortality when the WRL group $(P=.7273)$ and WRVL group $(P=.7646)$ were compared with the WRC group. Covariates associated with mortality include recipient creatinine at transplantation (hazard ratio [HR], 1.1; $P<.0001$ ), donor age (HR, 1.017; $P<.0001$ ), sex mismatch (HR, 1.191; $P=.0183$ ), race mismatch (HR, 1.124; $P=.004)$, and ischemia time (HR, 1.077; $P<.0001)$.

Female to male heart transplant. There are 2400 in the WRC group, 1187 in the WRL group, and 25 in the WRVL group. Kaplan-Meier analysis of the propensitymatched data set for female to male HTs is shown in Figure 2. The median survival for the WRC (3973 days) and WRL (3538 days) was significantly different $(P=.0241)$. Results of the Cox proportional hazards analysis, stratified by propensity score quartiles, are shown in Table 3. When compared with the WRC group, there was a significant difference in effect on mortality for WRL (HR, 1.208; 95\% confidence interval, 1.01-1.444; $P=.0383$ ), but not for WRVL $(P=.8484)$. Factors associated with 
TABLE 1. Summary of data set characteristics

\begin{tabular}{|c|c|c|c|c|}
\hline & $\begin{array}{c}\text { WR control: }>0.9 \\
(n=14,592)\end{array}$ & $\begin{array}{c}\text { WR low: }>=0.6-<0.9 \\
(n=7212)\end{array}$ & $\begin{array}{c}\text { WR very low: }<0.6 \\
(\mathrm{n}=124)\end{array}$ & $P$ value \\
\hline \multicolumn{5}{|l|}{ Recipient demographics } \\
\hline Recipient age, y & $52.0 \pm 12.6$ & $52.0 \pm 11.6$ & $52.0 \pm 11.0$ & .9729 \\
\hline Male recipient & $10,802(74.7)$ & $5790(80.3)$ & $96(77.4)$ & $<.0001$ \\
\hline Recipient ethnicity & & & & $<.0001$ \\
\hline White & $10,571(72.4)$ & $5434(75.4)$ & $95(76.6)$ & \\
\hline Black & $2349(16.1)$ & $1216(16.9)$ & $22(17.7)$ & \\
\hline Hispanic & $1091(7.5)$ & $422(5.9)$ & $6(4.8)$ & \\
\hline Asian & $433(3.0)$ & $74(1.0)$ & 0 & \\
\hline Other & $148(1.0)$ & $7(0.59)$ & $1(0.81)$ & \\
\hline Recipient BMI & $25.6 \pm 9.2$ & $30.1 \pm 36.9$ & $38.4 \pm 11.6$ & $<.0001$ \\
\hline Recipient diabetes & $1754(12.0)$ & $1019(14.2)$ & $14(11.3)$ & $<.0001$ \\
\hline Cardiac output at transplant & $4.4 \pm 1.5$ & $4.7 \pm 1.6$ & $4.9 \pm 1.4$ & $<.0001$ \\
\hline PVR at transplant & $2.6 \pm 2.1$ & $2.4 \pm 1.8$ & $2.4 \pm 1.8$ & $<.0001$ \\
\hline Creatinine at transplant & $1.4 \pm 0.9$ & $1.4 \pm 0.8$ & $1.5 \pm 0.8$ & .004 \\
\hline Ventilator at transplant & $456(3.1)$ & $195(2.7)$ & $6(4.8)$ & .1107 \\
\hline ECMO at transplant & $85(0.58)$ & $24(0.33)$ & $1(0.81)$ & .0437 \\
\hline \multicolumn{5}{|l|}{ Donor demographics } \\
\hline Donor age, y & $36.7 \pm 12.5$ & $35.0 \pm 12.9$ & $35.4 \pm 16.6$ & .0009 \\
\hline Male donor & $10,276(70.4)$ & $5238(72.6)$ & $84(67.7)$ & .0023 \\
\hline Donor ethnicity & & & & .0103 \\
\hline White & $1766(73.6)$ & $926(78.0)$ & $18(72.0)$ & \\
\hline Black & $331(13.8)$ & $101(8.5)$ & $5(20.0)$ & \\
\hline Hispanic & $256(10.8)$ & $127(10.7)$ & $1(4.0)$ & \\
\hline Asian & $22(0.92)$ & $17(1.4)$ & $1(4.0)$ & \\
\hline Other & $22(0.92)$ & $16(1.1)$ & 0 & \\
\hline Donor BMI & $30.1 \pm 6.7$ & $24.3 \pm 3.9$ & $19.3 \pm 3.0$ & $<.0001$ \\
\hline Donor diabetes & $111(4.6)$ & $28(2.4)$ & 0 & .011 \\
\hline \multicolumn{5}{|l|}{ Transplantation characteristics } \\
\hline Ischemia time, $\mathrm{h}$ & $3.2 \pm 1.0$ & $3.3 \pm 1.1$ & $3.0 \pm 1.0$ & .3543 \\
\hline Length of stay, $\mathrm{d}$ & $20.7 \pm 24.2$ & $22.2 \pm 30.1$ & $41.8 \pm 71.4$ & .0627 \\
\hline HLA mismatch & $4.6 \pm 1.04$ & $4.6 \pm 1.0$ & $4.7 \pm 1.2$ & .6191 \\
\hline Race mismatch & $948(39.5)$ & $420(35.4)$ & $10(40.0)$ & .0567 \\
\hline Sex mismatch & $4274(29.3)$ & $1822(25.3)$ & $38(30.7)$ & $<.0001$ \\
\hline
\end{tabular}

Data are given as mean $\pm \mathrm{SD}$ or number (\%). WR, Weight ratio; $B M I$, body mass index; $P V R$, pulmonary vascular resistance; $E C M O$, extracorporeal membrane oxygenation; $H L A$, human leukocyte antigen.

mortality were ischemia time (HR, $1.127 ; P=.0035)$, recipient creatinine level at transplantation (HR, 1.162; $P<.0001$ ), and donor age (HR, 1.014; $P=.0001)$.

\section{DISCUSSION}

Although HT remains an effective treatment for end-stage heart failure, ${ }^{1}$ a shortage of available organ donors has led to high mortality for patients awaiting HT. $^{22,23}$ Numerous attempts to extend the selection criteria for donors deemed suitable for transplant have been met with mixed results. ${ }^{2-9,11,12,14-16,18,24,25}$ In this study, we attempt to determine if International Society of Heart and Lung Transplantation guidelines regarding underweight HT donors could be extended. ${ }^{21}$

Extending the weight mismatch criteria for underweight donor hearts has been examined in previous studies ${ }^{4,18-20}$; however, there is lack of consensus regarding this issue. Patel and colleagues ${ }^{18}$ studied the donor to recipient weight ratio using the UNOS database in an analysis that included 2078 patients with a donor to recipient body weight ratio of less than 0.8. This study concluded that male to male, female to female, and male to female HT, with low donor to recipient weight ratio, was safe in certain populations. Our study set out to determine if this criterion could be extended to a donor to recipient body weight ratio of less than 0.8 . We determined that transplanting patients with a donor to recipient body weight ratio of less than 0.8 is not associated with increased mortality when transplanting male donors to male recipients, female donors to female recipients, and male donors to female recipients.

When transplanting female donor hearts to male recipients, a donor to recipient body weight ratio of greater than 0.9 is recommended by International Society of Heart and Lung Transplantation guidelines. In this study, independent analysis of female donors to male recipients with a donor to recipient body weight ratio of less than 

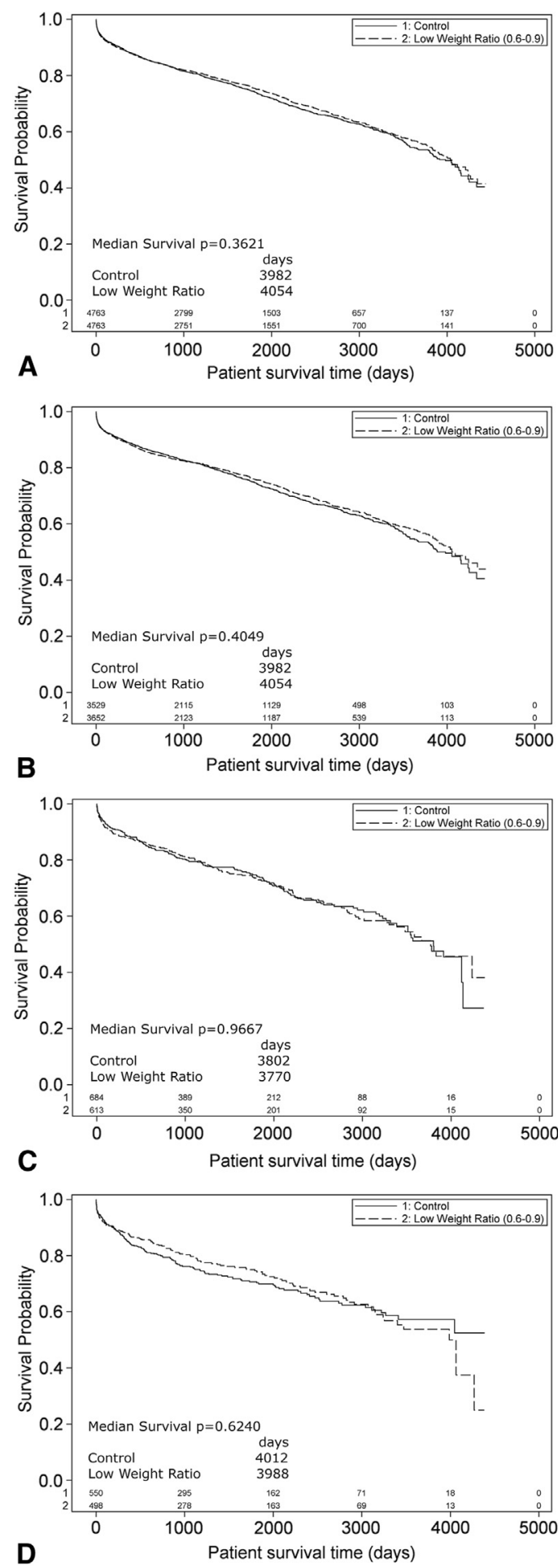

FIGURE 1. Kaplan-Meier survival analysis of sex-matched and male-tofemale transplantations, comparing control $(>0.9)$ with low-weight ratio (0.6-0.9). A, All transplantations (male to male, female to female, and male to female). B, Male-to-male transplantations. C, Female-to-female transplantations. D, Male-to-female transplantations.

0.9 demonstrated a reduction of median survival by 435 days on univariate survival analysis and a $20.1 \%$ increased
TABLE 2. Cox proportional hazards model for female-to-female HT, male-to-male HT, and male-to-female HT

\begin{tabular}{|c|c|c|c|c|}
\hline Predictors & $\begin{array}{c}\text { Hazard } \\
\text { ratio }\end{array}$ & $\begin{array}{r}95 \% \\
\text { Confidence } \\
\end{array}$ & limits & $\begin{array}{c}P \\
\text { value }\end{array}$ \\
\hline WRC $(>0.9)$ & REF & REF & REF & REF \\
\hline WRL (0.6-0.9) & 1.015 & 0.934 & 1.103 & .7273 \\
\hline WRVL $(<0.6)$ & 1.076 & 0.667 & 1.737 & .7646 \\
\hline Ischemia time & 1.077 & 1.039 & 1.117 & $<.0001$ \\
\hline $\begin{array}{l}\text { Recipient creatinine at } \\
\text { transplantation }\end{array}$ & 1.1 & 1.069 & 1.131 & $<.0001$ \\
\hline Male recipient & 0.907 & 0.814 & 1.011 & .0779 \\
\hline Recipient age & 0.998 & 0.994 & 1.001 & .1859 \\
\hline Donor age & 1.017 & 1.012 & 1.021 & $<.0001$ \\
\hline Recipient diabetes & 1.09 & 0.963 & 1.233 & .1711 \\
\hline Donor diabetes & 0.998 & 0.762 & 1.306 & .986 \\
\hline Pulmonary vascular resistance & 1.031 & 1.01 & 1.053 & .0041 \\
\hline Sex mismatch & 1.191 & 1.03 & 1.377 & .0183 \\
\hline Race mismatch & 1.124 & 1.038 & 1.217 & .004 \\
\hline
\end{tabular}

risk for mortality after adjusting for pertinent clinical factors on multivariate analysis. Previous studies have demonstrated this finding. ${ }^{18,20}$ Patel and colleagues ${ }^{18}$ showed that underweight female donors have worse mortality when transplanting male recipients with an elevated PVR. Further studies are needed to determine which subgroups of recipients and donors have worse survival when using underweight cardiac transplant donors. In this study, we examined transplants that were performed with a donor to recipient body weight ratio of less than 0.9 in female donors to male recipients. We determined that transplantation with female donor to male recipient weight ratios of less than 0.9 is associated with greater mortality risk than reduced median survival by longer than a year in this study. Weight is the most commonly used metric to match donors and recipients by size. However, other factors, such as body mass index and height, might be better standards for size matching potential donors to recipients. Further studies are needed to determine the best method of evaluating donor and recipient size matching.

Other factors associated with mortality on multivariate analysis in the female donor to male recipient group were longer ischemic time, increasing recipient serum creatinine level, and increasing donor age. In the other group of patients, increasing ischemic time, increasing recipient serum creatinine level, race mismatch, sex mismatch, and increasing donor age were associated with mortality, which coincides with findings of other studies. ${ }^{7,8,18}$

This study had a few limitations, including those related to retrospective analysis of large databases. All relevant variables, such as socioeconomic status and immunosuppressive regimens, are not available in UNOS, which might have a direct impact on survival. In addition, there is a 


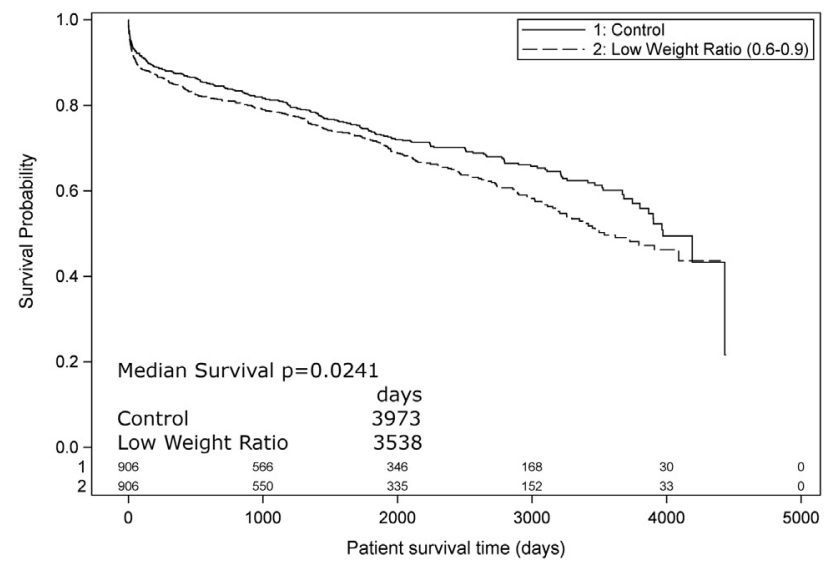

FIGURE 2. Kaplan-Meier survival analysis of female-to-male transplantations, comparing control (>0.9) with low-weight ratio (0.6-0.9).

TABLE 3. Cox proportional hazards model for female-to-male HT

\begin{tabular}{|c|c|c|c|c|}
\hline Predictors & $\begin{array}{c}\text { Hazard } \\
\text { ratio }\end{array}$ & $\begin{array}{r}95 \% \\
\text { Confidence }\end{array}$ & limits & $\begin{array}{c}P \\
\text { value }\end{array}$ \\
\hline WRC $(>0.9)$ & REF & REF & $\mathrm{REF}$ & REF \\
\hline WRL (0.6-0.9) & 1.208 & 1.01 & 1.444 & .038 \\
\hline WRVL $(<0.6)$ & 0.873 & 0.216 & 3.523 & .848 \\
\hline Ischemia time & 1.127 & 1.04 & 1.221 & .003 \\
\hline $\begin{array}{l}\text { Recipient creatinine at } \\
\text { transplantation }\end{array}$ & 1.162 & 1.086 & 1.244 & $<.000$ \\
\hline Recipient age & 0.996 & 0.988 & 1.003 & .280 \\
\hline Donor age & 1.014 & 1.007 & 1.022 & .000 \\
\hline Recipient diabetes & 1.29 & 0.979 & 1.699 & .07 \\
\hline Donor diabetes & 1.247 & 0.794 & 1.958 & .3383 \\
\hline Pulmonary vascular resistance & 1.006 & 0.959 & 1.055 & .805 \\
\hline Race mismatch & 1.152 & 0.965 & 1.374 & .1175 \\
\hline
\end{tabular}

$H T$, Heart transplantation; WRC, normal donor to recipient weight ratio; $R E F$, reference; $W R L$, donor to recipient body weight of $60 \%$ to $80 \%$; WRVL, donor to recipient body weight ratio of less than $60 \%$.

possibility of selection bias, because other factors, such as donor echo findings, donor central venous pressure, and descriptions of resuscitative efforts for the donor, are not readily available in the database. Finally, because of missing data, it was not feasible to include some variables into the multiple regression models for survival analysis and propensity matching. In addition, this analysis had a small sample size at the very-low-weight ratio $(<0.6)$, thus limiting power in this subgroup analysis.

In conclusion, although the current International Society of Heart and Lung Transplantation guidelines for weight mismatch was shown to be safe in a study using a national database, our study supports these findings and also shows that extending donor weight mismatch criteria to a greater degree ( $<40 \%$ mismatch for underweight donors) may be safe in male to male, female to female, and male to female heart transplants. In addition, our findings indicate that low donor to recipient body weight ratios of less than 0.9 may not be acceptable when a female organ donor is transplanted to a male recipient. Although this may hold for populationbased studies, decisions need to be made on a case-by-case basis.

\section{References}

1. Taylor DO, Edwards LB, Boucek MM, Trulock EP, Aurora P, Christie J, et al. Registry of the International Society for Heart and Lung Transplantation: twenty-fourth official adult heart transplant report-2007. J Heart Lung Transplant. 2007;26:769-81.

2. Ott GY, Herschberger RE, Ratkovec RR, Norman D, Hosenpud JD, Cobanoglu A. Cardiac allografts from high-risk donors: excellent clinical results. Ann Thorac Surg. 1994;57:76-82.

3. Marelli D, Bresson J, Laks H, Kubak B, Fonarow G, Tsai FC, et al. Hepatitis C-positive donors in heart transplantation. Am J Transplant. 2002;2:443-7.

4. Chen JM, Sinha P, Rajasinghe HA, Suratwala SJ, McCue JD, McCarty MJ, et al. Do donor characteristics really matter? short- and long-term impact of donor characteristics on recipient survival, 1995-1999. J Heart Lung Transplant. 2002;21:608-10.

5. Laks H, Marelli D, Fonarow GC, Hamilton MA, Ardehali A, Moriguchi JD, et al. Use of two recipient lists for adults requiring heart transplantation. $J$ Thorac Cardiovasc Surg. 2003; 125:49-59.

6. Lima B, Rajagopal K, Petersen RP, Shah AS, Soule B, Felker GM, et al. Marginal cardiac allografts do not have increased primary graft dysfunction in alternate list transplantation. Circulation. 2006;114(suppl):I27-32.

7. Stehlik J, Feldman DS, Brown RN, VanBakel AB, Russel SD, Ewald GA, et al. Interactions among donor characteristics influence post-transplant survival: a multi-institutional analysis. J Heart Lung Transplant. 2010;29:291-8.

8. Izquierdo MT, Almenar L, Martínez-Dolz L, Moro J, Agüero J, SánchezLázaro I, et al. Analysis of the impact of donor gender on early mortality. Transplant Proc. 2007;39:2375-6.

9. Taghavi S, Jayarajan SN, Wilson LM, Komaroff E, Testani JM, Mangi AA. Cardiac transplantation can be safely performed using selected diabetic donors [published online ahead of print March 12, 2013]. J Thorac Cardiovasc Surg. doi: pii: S0022-5223(13)00202-x.

10. Maltais S, Carrier M, Pellerin M, Perrault L. Closure of ventricular septal defects in the donor heart before transplantation: toward expanded acceptance criteria. J Thorac Cardiovasc Surg. 2005;129:1187-8.

11. Tenderich G, Koerner MM, Stuettgen B, Arusoglu L, Bairaktaris A, Hornik L, et al. Extended donor criteria: hemodynamic follow-up of heart transplant recipients receiving a cardiac allograft from donors $>$ or $=60$ years of age. Transplantation. 1998;66:1109-13.

12. Loebe M, Potapov EV, Hummel M, Weng Y, Bocksch W, Hetzer R. Mediumterm results of heart transplantation using older donor organs. J Heart Lung Transplant. 2000;19:957-63.

13. Blanche C, Kamlot A, Blanche DA, Kearney B, Magliato KE, Czer LSC, et al. Heart transplantation with donors fifty years of age and older. $J$ Thorac Cardiovasc Surg. 2002;123:810-5.

14. Russo MJ, Chen JM, Sorabella RA, Martens TP, Garrido M, Davies RR, et al. The effect of ischemic time on survival after heart transplantation varies by donor age: an analysis of the United Network for Organ Sharing database. J Thorac Cardiovasc Surg. 2007; 133:554-9.

15. Morgan JA, John R, Weinberg AD, Kherani AR, Colletti NJ, Vigilance DW, et al. Prolonged donor ischemic time does not adversely affect long-term survival in adult patients undergoing cardiac transplantation. J Thorac Cardiovasc Surg. 2003; 126:1624-33.

16. Mitropoulos FA, Odim J, Marelli D, Karandikar K, Gjertson D, Ardehali A, et al. Outcome of hearts with cold ischemic time greater than 300 minutes: a case-matched study. Eur J Cardiothorac Surg. 2005;28:143-8.

17. Kittleson MM, Shemin R, Patel JK, Ardehali A, Kawano M, Davis S, et al. Donor-recipient sex mismatch portends poor 10-year outcomes in a single-center experience. J Heart Lung Transplant. 2011;30:1018-22.

18. Patel ND, Weiss ES, Nwakanma LU, Russell SD, Baumgartner WA, Shah AS, et al. Impact of donor-to-recipient weight ratio on survival after heart transplantation analysis of the United Network for Organ Sharing database. Circulation. 2008;118(Suppl. 1):S83-8.

19. Sethi GK, Lanauze P, Rosado LJ, Huston C, McCarthy MS, Butman S, et al. Clinical significance of weight difference between donor and recipient in heart transplantation. J Thorac Cardiovasc Surg. 1993;106:444-8. 
20. Taghavi S, Wilson LM, Brann SH, Gaughan J, Mangi AA. Cardiac transplantation can be safely performed with low donor-to-recipient body weight ratios. J Card Fail. 2012;18:688-93.

21. Costanzo MR, Dipchand A, Starling R, Anderson A, Chan M, Desai S, et al. The International Society of Heart and Lung Transplantation Guidelines for the care of heart transplant recipients. J Heart Lung Transplant. 2010;29: 914-56.

22. Port FK, Dykstra DM, Merion RM, Wolfe RA. Organ donation and transplantation trends in the USA, 2003. Am J Transplant. 2004;4:7-12.
23. Pierson RN, Barr ML, McCullough KP, Egan T, Garrity E, Jessup M, et al Thoracic organ transplantation. Am J Transplant. 2004;4:93-105.

24. Lietz K, John R, Mancini DM, Edwards NM. Outcomes in cardiac transplant recipients using allografts from older donors versus mortality on the transplant waiting list: implications for donor selection criteria. J Am Coll Cardiol. 2004 43:1553-61.

25. Prendergast TW, Furukawa S, Beyer AJ III, Browne BJ, Eisen HJ, Jeevanandam V. The role of gender in heart transplantation. Ann Thorac Surg. 1998;65:88-94. 